
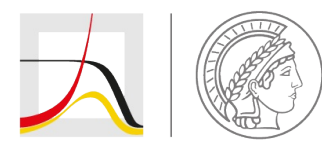

MAX PLANCK INSTITUTE

FOR DEMOGRAPHIC RESEARCH

Konrad-Zuse-Strasse 1 · D-18057 Rostock · Germany · Tel +49 (0) 3812081 - 0 · Fax +49 (0) 3812081 - $202 \cdot$ www.demogr.mpg.de

MPIDR Working Paper WP 2020-023 I May 2020

https://doi.org/10.4054/MPIDR-WP-2020-023

\title{
Multi-Platform Social Media Use: Little Evidence of Impacts on Adult Well-Being
}

Sophie Lohmann I lohmann@demogr.mpg.de Emilio Zagheni I sekzagheni@demogr.mpg.de 
Multi-Platform Social Media Use: Little Evidence of Impacts on Adult Well-Being

\author{
Sophie Lohmann ${ }^{\mathrm{a}}$ \\ Emilio Zagheni ${ }^{\text {a }}$ \\ ${ }^{\text {a }}$ Max Planck Institute for Demographic Research, Konrad-Zuse-Str. 1, 18057 Rostock, Germany
}

Corresponding author: Sophie Lohmann, Max Planck Institute for Demographic Research, Konrad-Zuse-Str. 1, 18057 Rostock, Germany, lohmann@demogr.mpg.de. SL and EZ conceived the research question and developed the modeling strategy. SL analyzed the data and wrote the manuscript. EZ edited and revised the manuscript.

Acknowledgments: We are grateful to Diego Alburez-Gutierrez, Samin Aref, Ugofilippo Basellini, Maarten J. Bijlsma, Emanuele del Fava, Denys Dukhovnov, Sofia Beatriz Gil, André Grow, Daniela V. Negraia, Francesco Rampazzo, Asli Ebru Sanlitürk, and Tom Theile for feedback on earlier versions of this manuscript.

Disclosures: The authors declare no competing interests. This research did not receive any specific grant from funding agencies in the public, commercial, or not-for-profit sectors. 


\begin{abstract}
Social media have become a near-ubiquitous part of our lives. The growing concern that their use may alter our well-being has been met with elusive scientific evidence. Existing literature often simplifies social media use as a homogeneous process. In reality, social media use and functions vary widely depending on platform and demographic characteristics of users, and there may be qualitative differences between using few versus many different social media platforms. Using data from the General Social Survey, an underanalyzed data source for this purpose, we characterize intensive social media users and examine how differential platform use impacts well-being. We document substantial heterogeneity in the demography of users and show that intensive users tend to be young, female, more likely to be Black than Hispanic, from high SES backgrounds, from more religious backgrounds, and from families with migration background, compared to both non-users and moderate users. The intensity of social media use seemed largely unrelated to well-being in both unadjusted models and in propensity-score models that adjusted for selection bias and demographic factors. Among middle-aged and older adults, however, intensive social media use may be slightly associated with depressive symptoms. Our findings indicate that although mediums of communication have changed with the advent of social media, these new mediums are not necessarily detrimental to well-being. Keywords: social networking sites, social media, well-being, mental health, digitalization
\end{abstract}


Multi-Platform Social Media Use: Little Evidence of Impacts on Adult Well-Being

\section{Introduction}

\subsection{Social Media Use and Well-Being}

Social media now play a major role in many areas of public and private life, including in how we get information, keep in touch with our social contacts, and meet new people. Despite seeming near-ubiquitous today, they were nearly unknown in mainstream culture 15 years ago (see boyd \& Ellison, 2007, for an early history) and in a short period of time, a large fraction of the US population has begun using a large variety of social media platforms: For example, $69 \%$ of the US population uses Facebook, 28\% use Pinterest, and Instagram use recently reached 37\% (Perrin \& Anderson, 2019). Facebook, which started as a network for ivy-league college students, is now the most widely used social network and has been adopted by people of all ages and education levels, similarly, social media use in general is now widespread across sociodemographic groups. Similar trends have occurred globally, and an estimated 3.8 billion people worldwide (or almost $50 \%$ of the global population) use some form of social media (we are social \& Hootsuite, 2020).

The rapid and widespread adoption of social media can be seen as a transformational process: On the one hand, it represents a change in form, by altering the medium through which we communicate. On the other hand, the change may go beyond form and additionally affect the quality of our interactions, the social support we receive from our networks, and subsequently our subjective well-being. In this work, we provide a new perspective on the under-studied implications of social media use for well-being, a topic that has drawn controversies in existing research but has rarely been examined in a nuanced way. In particular, it is so far unclear whether the intensity of social media use has a negative, positive, or null effect on well-being 
because of conflicting results and varying operationalizations (e.g., social media use as a unitary construct vs. number of platforms used). In defining social media, we adopt boyd and Ellison's description of "web-based services that allow individuals to (1) construct a public or semipublic profile within a bounded system, (2) articulate a list of other users with whom they share a connection, and (3) view and traverse their list of connections and those made by others within the system" (2007, p. 211; we use the terms social media and social networking sites synonymously in this article). We define subjective well-being (or well-being for short) as a multifaceted evaluation of one's own happiness that "includes satisfaction (both in general and satisfaction with specific domains), pleasant affect, and low negative affect" (Diener et al., 2003, p. 189). We will therefore include indices of pleasant affect such as happiness, unpleasant affect such as depressive symptoms, and domain-specific satisfaction such as subjective health. Due to the concerns that social media use may reduce life satisfaction specifically regarding social matters, we place special focus on social well-being, including relationship satisfaction and trust in society (Helliwell \& Putnam, 2004).

There is disagreement over whether differences in the form of communication (on social media versus offline) also change communication's function in well-being. In the present analysis, we examine a nationally representative data source, a larger variety of social media platforms, and a larger variety of well-being indicators than most previous studies have considered, in order to answer the questions of whether the communication patterns of social media users are associated with lower well-being than those of people who do not use social media, and whether the communication patterns of intensive social media users (defined as those who use a large number of platforms) are, in turn, associated with lower well-being than those of less intensive users. 
Existing literature often conceptualizes internet use and social media use as homogeneous processes, in part because of the available data which are often simple aggregate measures of whether a person uses any social media platform or how much time they spend online. Social media use and functions, however, vary widely depending on the platform and the socioeconomic/demographic characteristics of users. For instance, in contrast to some studies showing negative associations with well-being, multiple studies have found that social media use can instead enhance the well-being of young populations by fostering social support and social inclusion, including in Turkish high school students (Doğan, 2016), Korean college students (Park et al., 2009), and US young adults (Hardy \& Castonguay, 2018). However, because much of the discussion on whether social media harms well-being has been centered around teenagers, there is comparatively little information on how young, and especially middle-aged and older adults may be affected. The current literature shows a gap in our knowledge of the associations between multi-platform social media use and well-being across demographic groups. One of the contributions of this paper is to close this gap by evaluating how heterogeneous use of social media, including intensity of multi-platform social media use, differentially affects the wellbeing of adults in different demographic groups, especially across age.

\subsection{Multi-Platform Use}

We are focusing on multi-platform use (i.e., the number of social media platforms that a person uses) because it can indicate how strong the presence of social media is in a given person's life and how many potential benefits (such as opportunities for social support), but also how many stressors (such as upsetting news) somebody is exposed to through social media. Multi-platform use should be correlated with, but not synonymous to, time spent on social media: On average, people who use many platforms are likely to spend more time on social 
media in total, but somebody who uses just one platform extensively may spend just as much time on social media. Instead, multi-platform use indicates in how many qualitatively different ways people interact with social media, and is thus a proxy for the number of areas in which a person's life is linked to social media. A person who has a Facebook account to keep in touch with family and a LinkedIn profile to connect with colleagues interacts with social media in fewer areas of their life than somebody who is on Facebook for family, LinkedIn for work, Instagram for food blogging, Twitter for news, Pinterest for cooking inspiration, and Snapchat for contact with friends. Despite the potential relevance to well-being, multi-platform use has drawn comparatively little research attention to date.

1.2.1 Potential detrimental effects. In the previous example, the person who uses more platforms may lose out on sleep or experience fewer face-to-face social contacts (Kraut et al., 1998; Levenson et al., 2016). They may also be exposed to more social conflicts, upsetting news, and posts about others' successes that elicit social comparison processes (e.g., Faranda \& Roberts, 2019; Wang et al., 2017). Assuming that social conflicts (Abbey et al., 1985; Lepore, 1992), upsetting news (Szabo \& Hopkinson, 2007; Veitch \& Griffitt, 1976), and upward social comparisons (H. Appel et al., 2016; Gerber et al., 2018; Myers \& Crowther, 2009) make people less satisfied with their lives, we could expect lower well-being for those who use many social media platforms than for those who use fewer of them. Past literature does suggest that multiplatform use may be linked to stronger symptoms of depression and anxiety (Hardy \& Castonguay, 2018; Primack et al., 2017; Vannucci et al., 2019), but overall few studies have investigated the impact of multi-platform social media use. Similarly, a displacement effect of internet use on social well-being has been suggested. This means that more time spent on online activities leads to less time spent on offline social interactions, which in turn reduces well-being 
(Kraut et al., 1998; Nie, 2001) (but see Hall et al., 2019; Kraut et al., 2002; Valkenburg \& Peter, 2007, for disconfirmations of this effect), but the existence of such a displacement effect has not yet been studied with regards to multi-platform use.

1.2.2 Potential positive or null effects. Alternatively, however, the frequency and breadth of social media platform use may matter less than what these platforms are used for (e.g., Bessière et al., 2010; Park et al., 2009; Rae \& Lonborg, 2015; Valkenburg et al., 2006). In offline life, one person may form large social networks, another person may have fewer social contacts and perhaps spend more time reading the news instead, and yet another person might spend a lot of time watching TV. If those three people take to social media, they may continue the same activities, simply on another medium (Tyler, 2002) - for example, using Facebook to keep in touch with friends, to read and discuss news articles, or to watch videos, respectively. If, in this way, social media changes the surface form of activities more than the functions they fulfill, we would not expect consistent negative or positive effects on well-being. This account is supported by a number of studies and reviews that find null effects or only small effect sizes (M. Appel et al., 2019; Coyne et al., 2020; e.g., meta-analytic r = -.07, Huang, 2017; Jensen et al., 2019; Orben et al., 2019; Orben \& Przybylski, 2019) of social media use on well-being, as well as by multiple studies that examine the direction of this association. Although it has often been argued that social media make people lonelier, more depressed, and less satisfied with their life (e.g., Kross et al., 2013; Twenge et al., 2018; Twenge \& Campbell, 2019), it could also be that lonely, depressed, and unhappy people (or people who are simply more introverted) are more likely to self-select into using social media as a means of forming new relationships, finding communities that provide social support, and coping with negative affect (e.g., Fergie et al., 2016; Gowen et al., 2012; K. M. Griffiths et al., 2009; Lee et al., 2013; Selkie et al., 2019). Despite the fact that 
these two processes are not mutually exclusive, mounting evidence suggests that this selfselection process may play a stronger role than the opposite causal pathway (Aalbers et al., 2019; Song et al., 2014; van der Velden et al., 2019). In that case, there may be no causal effect of social media use on well-being, and potentially even a positive effect if lonely people use social media to form new social ties or to strengthen existing ties (Ellison et al., 2007; Yu et al., 2016), which is in turn associated with improved health (e.g., Berkman \& Syme, 1979; Pinquart \& Sörensen, 2000).

In this paper, we provide new insights into the relationship between social media and well-being using data from the General Social Survey (GSS), which is one of the most authoritative studies of societal change in the US and provides a rich, yet almost untapped resource for this purpose. To our knowledge, only one single paper previously used this data to examine well-being and social media use. However, that paper focused on only a third of the social media platforms and on only one out of seven well-being variables that were available in the data (Hardy \& Castonguay, 2018). With this article, we challenge some of the results previously shown in the literature by offering a more comprehensive picture of multi-platform social media use, including an examination of number and types of platforms and their relationship to socio-demographic characteristics, and multiple indicators of well-being. We also provide a more rigorous adjustment for selection bias by using inverse-probability of treatment weighting (IPTW, a propensity-score adjustment method) to a field which has typically used simpler, but possibly biased models. If factors such as age or socio-economic status give people both a higher propensity to be unhappy and a higher propensity to be intensive social media users (e.g., Diener \& Suh, 1997; Luo \& Waite, 2005; Perrin \& Anderson, 2019), simple regression models may reveal a negative correlation between happiness and multi-platform use, even when 
in truth this relation is spurious and caused by self-selection bias. IPTW offers an approach for controlling for a portion of this bias and can thus help disentangle spurious and substantive effects.

To summarize, this paper aims to contribute to the ongoing discussion on whether social media use is harmful for people's well-being by examining the under-studied construct of multiplatform use: 1) Characterizing the socio-demographic characteristics of multi-platform users, 2) studying how multi-platform use relates to well-being, 3) examining effects across the lifespan rather than focusing just on young adults, 4) looking at the effects of specific social media platforms rather than assuming that all have equal effects on well-being, and 5) addressing potential self-selection bias by applying state-of-the-art propensity-score approaches. We discuss these methods next.

\section{Method}

We use the 2016 wave of the GSS, the first and so far the only wave to include a social media module. The GSS comprises predominantly face-to-face interviews (English or Spanish) conducted between April and November of 2016, targeting adults living in households in the US (Smith et al., 2019). A total of $N=1,372$ respondents were asked about their social media use, and on average, they were 43 years old $(S D=16)$ and $56 \%$ of them were women. Most participants (69\%) were Non-Hispanic White, 14\% were Non-Hispanic Black, $13 \%$ identified as Hispanic, and 5\% reported another race. Because in the GSS, not all questions are shown to all respondents, sample sizes for individual analyses may differ (see Supplementary Materials for a table of sample sizes per variable). The GSS uses an area-probability cluster sample with twostage sub-sampling for nonresponse with weights and is designed to produce results that are representative of the US population when taking these weights into account. The results in this 
report are based on design-corrected standard errors that incorporate design weights and nonresponse weights (incorporating variables VSTRAT for variance stratum and WTSSALL for weights). The weighted correlations and associated p-values presented in this manuscript are based on bootstrap calculations.

\subsection{Variables}

2.1.1 Online activity. Respondents were asked whether they used each of the following platforms: Twitter (a microblogging website focused on short messages, usually used to interact with the wider public), Facebook (a social network, usually used to interact with friends and family), Instagram (an image-based platform, used variably but often to interact with the wider public and/or influencers), LinkedIn (a social network, usually used to interact with business contacts), Snapchat (an image-based instant-messaging platform where images auto-delete after a few seconds, usually used to interact with friends), Tumblr (a micro-blogging platform, usually used to interact with the wider public), WhatsApp (an instant-messaging platform, usually used to interact with friends and family) ${ }^{1}$, Google+ (a social network, now defunct), Pinterest (an image-based platform, usually used to create image collections or inspiration boards), Flickr (an

${ }^{1}$ WhatsApp may be seen as a special case as it can be used either as simply a texting service, which would not fulfill our definition of a social media platform, or as a social media platform (by joining public or semi-public groups and, since 2017, posting status updates). In the absence of data on how participants used the service, we included WhatsApp as a social media platform here, but also repeated all analyses excluding WhatsApp. The results overwhelmingly stayed the same, with two exceptions: Gender no longer predicted whether someone was an intensive user, $p=.079$ (but still predicted overall number of used platforms) and the interaction between age and number of platforms on social trust was no longer significant, $p=.054$. 
image-hosting service, usually used to share or view photos), Vine (a video-based platform for six-second videos, now defunct), and Classmates (a social network, usually used to interact with former class members and colleagues), plus space for free-form responses (we excluded online gaming, online dating sites, and Spotify from these responses). These variables were binary (with 1 indicating that a given platform is used) and by summing them, we derived a continuous index of multi-platform social media use ranging from 0 to $14(M=2.84, S D=2.06)$. These social media variables were treated as missing for people who reported not using the internet at all (and therefore could not be on social media). We also used variables in which respondents had indicated how many hours and minutes they used the internet (not just social media) on a typical weekday and a typical weekend day, a variable that indicated which social media platform the participant had joined first, and a variable that indicated when the respondent had joined this first platform. We used the latter variable to obtain the number of years for which the respondent had been using social media and to calculate the proportion of their life that they had spent using social media. These indices should be interpreted as approximate indications of how long respondents had used social media, but not necessarily as accurate indices because retrospective recall of this sort appeared difficult and imprecise: A substantial number of respondents $(n=$ 101) gave implausible responses, e.g., claiming to have been using Instagram (which launched in 2010) since 2006 or Facebook (which launched in 2004) since 1985 (these impossible responses were treated as missing).

\subsubsection{Offline social activity. The survey also asked how often respondents spent an} evening with relatives, with friends, with neighbors, and in bars. The items were scored in such a way that they reflect the approximate weekly frequency (e.g., "several times a month" would be between 2 and 5 times a month, which on average would be 3.5 times a month and 0.81 times a 
week; similar patterns occurred when using more liberal or more conservative ways of scoring the frequencies). The four items were summed up to create an overall index of offline social activity.

2.1.3 Personal Well-being variables. The survey further included several questions that can be used as indicators of subjective well-being, one that measured general happiness (Taken all together, how would you say things are these days--would you say that you are very happy, pretty happy, or not too happy?, respectively coded as 1,0 , and -1), one that measured general health condition (Would you say your own health, in general, is excellent, good, fair, or poor?, respectively coded as $2,1,0$, and -1), and one that measured whether respondents perceived life as exciting or dull (In general, do you find life exciting, pretty routine, or dull?, respectively coded as 1 and -1). Although these questions provide only a subjective assessment of wellbeing, prior research has found that people's responses to such subjective single-item questions are strongly predictive of these people's future mortality (see DeSalvo et al., 2006, for a metaanalysis; and Schnittker \& Bacak, 2014, for an analysis of the GSS, specifically). One more question asked participants to rate their financial satisfaction. Although this index was naturally associated with income $(r=0.35)$, the correlation was not strong enough to see financial satisfaction as a mere proxy for income. All items had three or four response options and were scored such that positive responses (e.g., Excellent, Very happy) received positive values, neutral or middle responses (e.g., Fair, Pretty happy) received a value of 0, and negative responses (e.g., Poor, Not too happy) received negative values.

Further, a 5-item version of the Center for Epidemiologic Studies Depression (CES-D) Scale (Radloff, 1977) was administered to measure depressive feelings (feeling depressed, happy (reverse-coded), lonely, sad, and experiencing restless sleep) during the preceding week. The 
items ranged from $0=$ None or almost none of the time to $3=$ All or almost all of the time and formed an internally consistent index, Cronbach's $\alpha=0.76$ (Cronbach, 1951), and were thus averaged into a composite score ${ }^{2}$.

Finally, one question asked whether the respondent had ever felt like they were going to have a mental breakdown, and one question asked respondents to indicate how many of the days in the past month their mental health had not been good. Closer examination of these two items, however, raises potential doubts about their validity. The item on breakdown propensity did not explain to respondents what a "mental breakdown" meant, likely leading to considerable variation in subjective definitions of a vague concept and the item referred to the respondents' entire lifespan, making it unsuitable for the analysis of recent phenomena (such as the widespread adoption of social media) and current well-being. In fact, this item showed only lowto-medium correlations with all other indicators of well-being in the survey, $r=-.14$ with happiness, $r=-.17$ with health, $r=.31$ with depression, and $r=.25$ with bad mental health days. The item on bad mental health days was noisy (e.g., several people rated themselves as "very happy" despite indicating that 30 out of the last 30 days had been bad mental health days for them) and difficult to validate. In fact, the number of bad mental health days seemed more closely related to self-rated physical health, $r=-0.32$, than to happiness, $r=-0.27$, whereas the CES-D depression scale (a well-validated and widely-used questionnaire) showed the opposite pattern. The items are still included in the analyses for completeness's sake and for comparison with a previous study of the breakdown variable (Hardy \& Castonguay, 2018), but should be interpreted with caution.

${ }^{2}$ Examining the items on depressed mood (depressed, happy, sad), loneliness, and restless sleep separately did not produce notable changes to the results. 
2.1.4 Social well-being variables. Two questions asked about participants' happiness in their marriage (if they were married) or happiness in their relationship with their partner (if they had a partner). Because respondents answered at most one of these questions (none if they were single), we combined them into one index of relationship satisfaction. Respondents also indicated on three different items whether they considered people in general helpful vs. looking out for themselves, fair vs. likely to try and take advantage, and trustworthy vs. "can't be too careful". These items were averaged to obtain a composite index of social trust, Cronbach's $\alpha=$ 0.65. Another set of 15 items asked respondents to rate their confidence in various social institutions, such as major companies, organized religion, education, television, the scientific community, or congress. These variables were moderately to strongly associated with each other and we averaged them to obtain a composite index of social confidence, Cronbach's $\alpha=0.78$. The social well-being variables all had three response options and were scored such that the positive response received a value of 1 , the neutral response received a value of 0 , and the negative response received a value of -1 .

2.1.5 Socio-demographic characteristics. One of the aims of this study was to describe socio-demographic characteristics of intensive and less intensive social media users. The GSS includes a rich variety of demographic variables which facilitated these analyses: Respondents indicated their gender, age (in years, but the oldest participants were grouped into 89 or older, which was counted as 89 in the analyses) ${ }^{3}$, race (White, Black, Other) and ethnicity

${ }^{3}$ Including age as a categorical variable (with groups 18-29, 30-39, 40-49, and so on) instead of a continuous variable to account for non-linear effects did not appreciably change results. Only the effect of number of platforms on the mental breakdown variable, which we already discuss elsewhere, became additionally significant. 
(Hispanic/Latino/Latina or not), household size, and number of children. The interviewer coded the approximate size of the respondent's place of living. To reduce the number of highly correlated variables, we created several summary indices, starting with an index of socioeconomic status by standardizing and averaging income, occupational prestige, employment status (employed/not employed and full-time employed/not full-time), whether participants had a college degree, and subjective social rank (recoded so that $1=$ bottom and $10=$ top $)$. Similarly, we created a foreign-family index out of each participant's number of foreign-born grandparents, whether one of their parents was foreign-born, and whether they themselves were born abroad, an index of religiosity out of strength of religious affiliation, frequency of attending worship, and frequency of attending religious events other than worship, as well as an index of political conservatism out of self-rated conservatism and whether the participant had voted (or intended to vote) conservative in the 2012 presidential election.

\subsection{Analysis Procedure}

To compare intensive social media users with moderate social media users and non-users, we grouped respondents based on how many platforms they reported using $(0,1-5,6+$; cut-offs representing the $10^{\text {th }}$ and $90^{\text {th }}$ percentile, respectively). For our initial comparison, we used t-tests that compared intensive users with everyone else. Following prior research, we examined the associations between social media use and well-being using correlations (for bivariate relations) and regression approaches (for multi-factor prediction). For better interpretability, outcomes and continuous predictors were z-standardized and we therefore present standardized linear regression coefficients. An important innovative aspect of our analyses is that we include rigorous tests of the association between social media use and well-being by accounting for 
potentially confounding variables and attempting to gain deeper causal insights by using methods such as propensity score adjustment.

\section{Results}

\subsection{The Demography of Social Media Users}

3.1.1 Prevalence. Social media use was highly prevalent in the 2016 GSS data; as a matter of fact, only $11 \%$ of respondents were not on social media (numbers are adjusted for design and non-response weights; rounding means estimates may not sum up to 100). Typically, respondents used between 1 and 5 different platforms. However, a minority of respondents reported using 6 platforms or more. We termed this group of respondents intensive social media users (6+ platforms; $11 \%)$ and used t-tests to evaluate which socio-demographic characteristics differentiate them from both moderate users (1-5 platforms; 79\%) and non-users (0 platforms; $11 \%)$

3.1.2 General characteristics. To predict the probability of being an intensive social media user (as opposed to a moderate or non-user) while controlling for other demographic characteristics, we conducted a logistic regression with city size, household size, gender, age, number of children, race/ethnicity, the SES index, the foreign-family index, the religiosity index, and the political conservatism index as predictors (continuous predictors were centered and standardized for ease of interpretation). Consistent with prior findings (e.g., Perrin \& Anderson, 2019), social media users in general tended to be younger than non-users, and intensive social media users were again younger than moderate users, $O R=0.5395 \% \mathrm{CI}[0.41,0.67]$ (see Table 1 and Figure 1). Social media users in general were also substantially more likely to be female than non-users, and intensive social media users were more likely to be female than everyone 
else, $O R=1.6395 \%$ CI $[1.09,2.43]$. To illustrate, women made up $63 \%$ of intensive users in this sample, but only $57 \%$ of moderate users and $40 \%$ of non-users.

Regarding race and ethnicity, Hispanic participants were generally less likely to be intensive users, but only the contrast with Non-Hispanic Black participants reached statistical significance, $O R=0.3495 \% \mathrm{CI}[0.15,0.76]$. People with high socio-economic status, $O R=1.56$ $95 \%$ CI $[1.27,1.92]$, more foreign-born family members, $O R=1.2695 \%$ CI $[1.01,1.58]$, and higher religiosity, $O R=1.2995 \% \mathrm{CI}[1.06,1.57]$, were all more likely to be intensive social media users. Finally and as expected, intensive social media users had started using social media earlier both in absolute terms (year of start), $t(62)=-4.23, p<.001$, and in relative terms (proportion of life using social media), $t(62)=5.33, p<.001$, compared to their more moderately-using counterparts. They also reported using the internet for almost an hour longer on both weekdays, $t(62)=3.74, p<.001$, and weekend days, $t(62)=3.34, p=0.001$, than either non-users or moderate users. Results were similar when using the continuous number of used platforms as an outcome instead of classifying users as intensive versus not (see Supplemental Materials). 

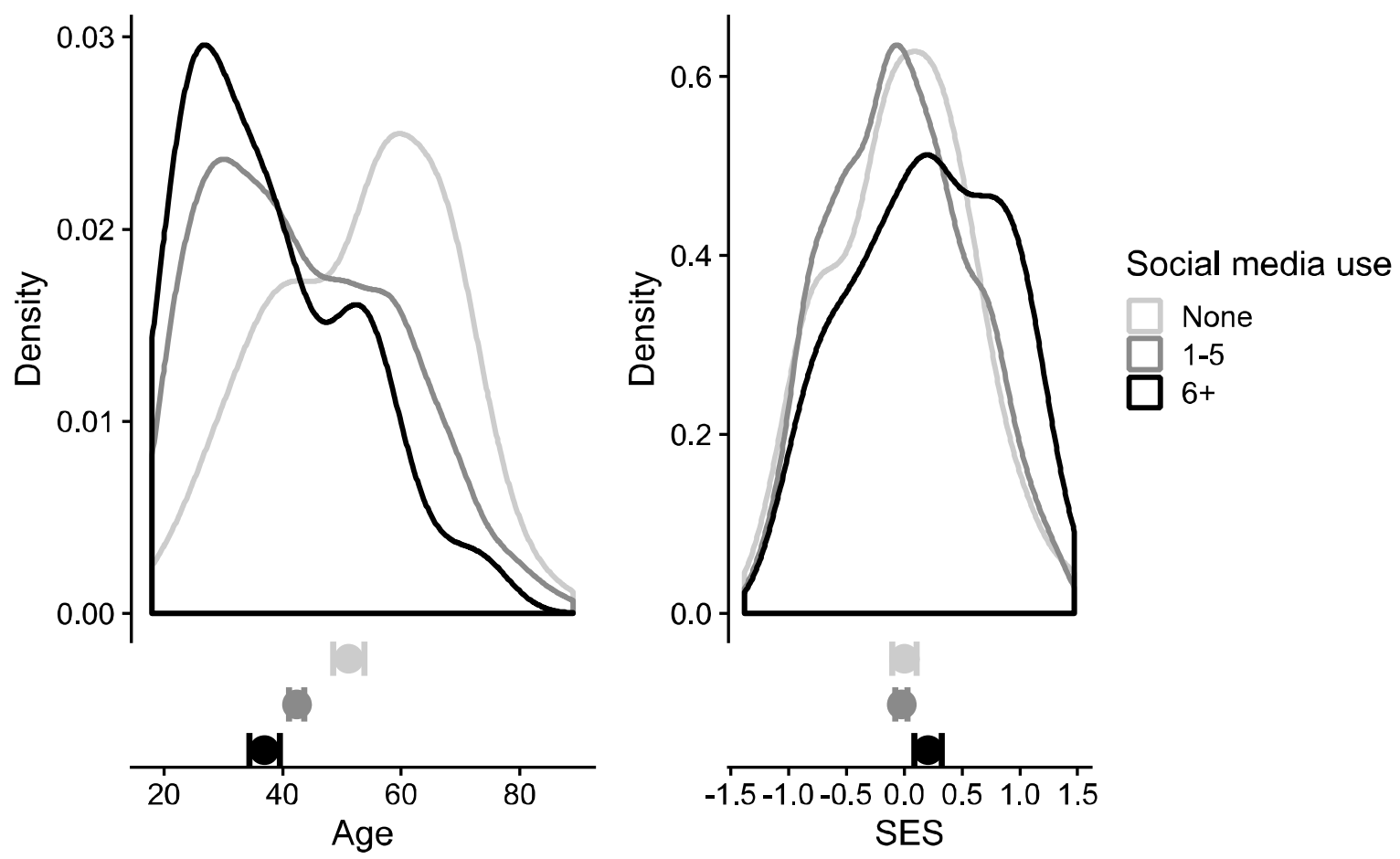

Figure 1. Weighted density curves, means, and 95\% CI error bars of age and SES by social media use.

Table 1

Regressions of demographic predictors on intensive usage (logistic regression for binary outcome, linear regression for continuous number of platforms). Continuous predictors are centered and standardized, the original standard deviations are presented in the right-hand column.

\begin{tabular}{|c|c|c|c|c|c|}
\hline \multirow[b]{2}{*}{ Predictor } & \multicolumn{2}{|c|}{ Intensive user (binary) } & \multicolumn{2}{|c|}{ Number of platforms } & \multirow[b]{2}{*}{$S D$} \\
\hline & OR & $\mathrm{CI}$ & $b$ & CI & \\
\hline Intercept & 0.10 & {$[0.07,0.13] * * *$} & 2.98 & {$[2.84,3.13] * * *$} & \\
\hline City size (std.) & 1.16 & {$[0.95,1.43]$} & 0.15 & {$[0.02,0.28] *$} & 42835.27 \\
\hline Household size (std.) & 0.92 & {$[0.74,1.13]$} & -0.08 & {$[-0.21,0.04]$} & 1.35 \\
\hline Gender: Male & 0.61 & {$[0.41,0.91] *$} & -0.70 & {$[-0.91,-0.48] * * *$} & 0.50 \\
\hline Age (std.) & 0.53 & {$[0.41,0.67] * * *$} & -0.74 & {$[-0.86,-0.61] * * *$} & 16.02 \\
\hline Nr of children (std.) & 0.91 & {$[0.74,1.12]$} & -0.09 & {$[-0.23,0.05]$} & 1.48 \\
\hline
\end{tabular}




\begin{tabular}{lrlrll} 
Race/Ethn.: Hispanic & 0.54 & {$[0.25,1.16]$} & -0.41 & {$[-0.77,-0.04] *$} & 0.32 \\
Race/Ethn.: Non-Hispanic Black & 1.59 & {$[0.95,2.64]$} & 0.07 & {$[-0.31,0.45]$} & 0.35 \\
Race/Ethn.: Non-Hispanic Other & 0.90 & {$[0.35,2.27]$} & 0.16 & {$[-0.50,0.82]$} & 0.21 \\
SES index (std.) & 1.56 & {$[1.27,1.92] * * *$} & 0.23 & {$[0.11,0.35] * * *$} & 0.60 \\
Foreign family index (std.) & 1.26 & {$[1.01,1.58] *$} & 0.17 & {$[-0.02,0.35]$} & 0.87 \\
Religiosity index (std.) & 1.29 & {$[1.06,1.57] *$} & 0.15 & {$[0.04,0.26] *$} & 0.84 \\
Political conservatism index (std.) & 0.86 & {$[0.68,1.07]$} & -0.08 & {$[-0.20,0.04]$} & 0.87 \\
\hline$* p<.05, * * p<.01 * * * p<.001$ & & & &
\end{tabular}

$* p<.05, * * p<.01, * * * p<.001$

\subsection{Multi-Platform Social Media Use and Well-Being}

Table 2

Correlations (r) of social media use, offline social contact, and personal and social well-being.

\begin{tabular}{lcc}
\hline & $\begin{array}{c}\text { Social } \\
\text { media use }\end{array}$ & $\begin{array}{c}\text { Offline social } \\
\text { contact }\end{array}$ \\
\hline Happiness & .01 & .03 \\
Health & .02 & .06 \\
Depression & .04 & + \\
Bad mental health days & .07 & .07 \\
Ever feel like breakdown & $.13^{*}$ & .03 \\
Exciting vs. dull life & $.08^{*}$ & $.13^{*}$ \\
Financial satisfaction & -.01 & -.02 \\
Relationship satisfaction & .06 & .05 \\
Social trust & -.01 & -.12 \\
Confidence in social institutions & .06 & .06 \\
Offline social contact & $.13^{*}$ & \\
\hline
\end{tabular}

$* p<.05$

${ }^{+}$could not be calculated because the variables were never administered in the same questionnaire

We examined the association between intensity of social media use (number of used platforms) and well-being, and also compared these results with the relation between offline social contacts and well-being for discriminant validity. ${ }^{4}$ Overall, there were no detrimental

\footnotetext{
${ }^{4}$ Here we present bivariate results for easy interpretability. Supplementary Table 3 shows
} a set of additional analyses in which we controlled for the same set of socio-demographic 
associations of social media use with various indicators of personal well-being including happiness, health, depression, or the number of bad mental health days (Table 2). More specific forms of well-being such as financial satisfaction or excitement about life were also not decreased by social media use - in fact, rather than experiencing negative consequences, people who used more social media found their life slightly more exciting. The same result, however, was observed for offline social contact. Thus, increased interest in one's own life may represent a consequence (or cause) of a more active social life rather than a feature that is specific to online media. The only well-being indicator that was negatively impacted by multi-platform social media use was the chance of ever having felt, in one's life, that one would have a mental breakdown, and it was this item that led Hardy and Castonguay (2018) to conclude that social media negatively affects well-being. As mentioned previously, however, the validity of this item is questionable because the concept of a mental breakdown was ill-defined and the item did not show strong concurrent validity with other indicators of well-being or mental health. Further, this item was the only one that referred to respondents' entire lifespan instead of current well-being. If the correlation between this item and social media use is seen as a valid and non-spurious result, it would therefore suggest reverse causation: If lifespan mental health relates to social media use but current mental health doesn't, the most likely explanation is that earlier mental health problems led people to self-select into social media instead of social media affecting wellbeing.

variables as discussed previously. In these analyses, none of the subjective well-being indicators was predicted by number of social media platforms. Among the social well-being indicators, relationship satisfaction and social trust were significantly higher among respondents who used more social media platforms. 
Intensity of social media use seemed similarly unrelated to social well-being, as there were no negative (or positive) associations with relationship satisfaction with respondents' romantic partners, social trust in people in general, or confidence in various social institutions. Finally, there was no evidence of a displacement effect for social support either: Online and offline social activity frequency were modestly positively correlated instead. In other words, people who used social media intensively did not appear to compensate this by reducing their offline social contact. Instead, it appears likely that people high in extraversion would seek both online and offline social contact, thus producing the observed positive correlation.

The results did not change when comparing intensive social media users ( $6+$ platforms) to more moderate and non-users, with two exceptions: Intensive users reported higher satisfaction with their romantic relationship and more confidence in social institutions than other respondents. Additionally, the previously discussed positive finding of social media users considering life more exciting than non-users $(M=0.51,95 \% \mathrm{CI}[0.37,0.64])$ appeared to be driven by intensive $(M=0.63,95 \% \mathrm{CI}[0.50,0.76])$, but not moderate users $(M=0.47,95 \% \mathrm{CI}$ $[0.41,0.53])$.

\subsection{Multi-Platform Social Media Use and Well-Being Across Age}

Multi-platform use was substantially influenced by age and because some prior literature has found interactions of multi-platform use with age (Hardy \& Castonguay, 2018),we repeated these analyses including age as an additional predictor and a moderator. Out of the ten wellbeing variables we examined, there were eight for which social media use intensity was unrelated to well-being in interaction with age $(p s=.157-959)$. One of these variables for which we found no such interaction $(\beta=0.06, S E=0.04, p=.157)$ one was whether respondents had ever felt like they were going to have a mental breakdown, which was the variable for which 
Hardy and Castonguay had reported an interaction (they used only four of the available social media platforms, whereas we used all available indicators of social media use). For depression, middle-aged to older adults (top three quartiles of age, everyone over 34) report marginally higher depression with higher social media use, $r=-.09, p=.054$, but for younger adults (lowest quartile, 34 and younger), depression and social media use were unrelated, $r=.08, p=.152$ (Figure 3; interaction $\beta=0.10, S E=0.04, p=.016)^{5}$. In addition, for social trust, the top three age quartiles $(>34)$ report higher social trust with higher social media use $r=.09, p=.004$, but young adults do not, $r=-.01, p=.738$ (interaction $\beta=0.06, S E=0.03, p=.035$ ). Three more variables showed no interaction between age and social media use, but were predicted by a main effect of social media use after controlling for mean-centered age: These included ever having felt like one would have a breakdown (the same negative association as in the bivariate results; $\beta$ $=0.10, S E=0.04, p=.017$ ), finding one's life exciting (the same positive association as in the bivariate results; $\beta=0.10, S E=0.04, p=.020$ ), and confidence in social institutions (positive association with social media use; $\beta=0.06, S E=0.03, p=.022$ ). After accounting for age, most results therefore did not change; the exceptions were the results for depression (negative association with social media use in older, but not younger people), social trust (positive association with social media use in younger, but not older people) and confidence in social institutions (positive association).

${ }^{5}$ Examining the items on depressed mood (depressed, happy, sad), loneliness, and restless sleep separately showed that this interaction was driven by depressed mood. The items on loneliness and restless sleep showed neither a main effect of multi-platform use nor an interaction with age. 


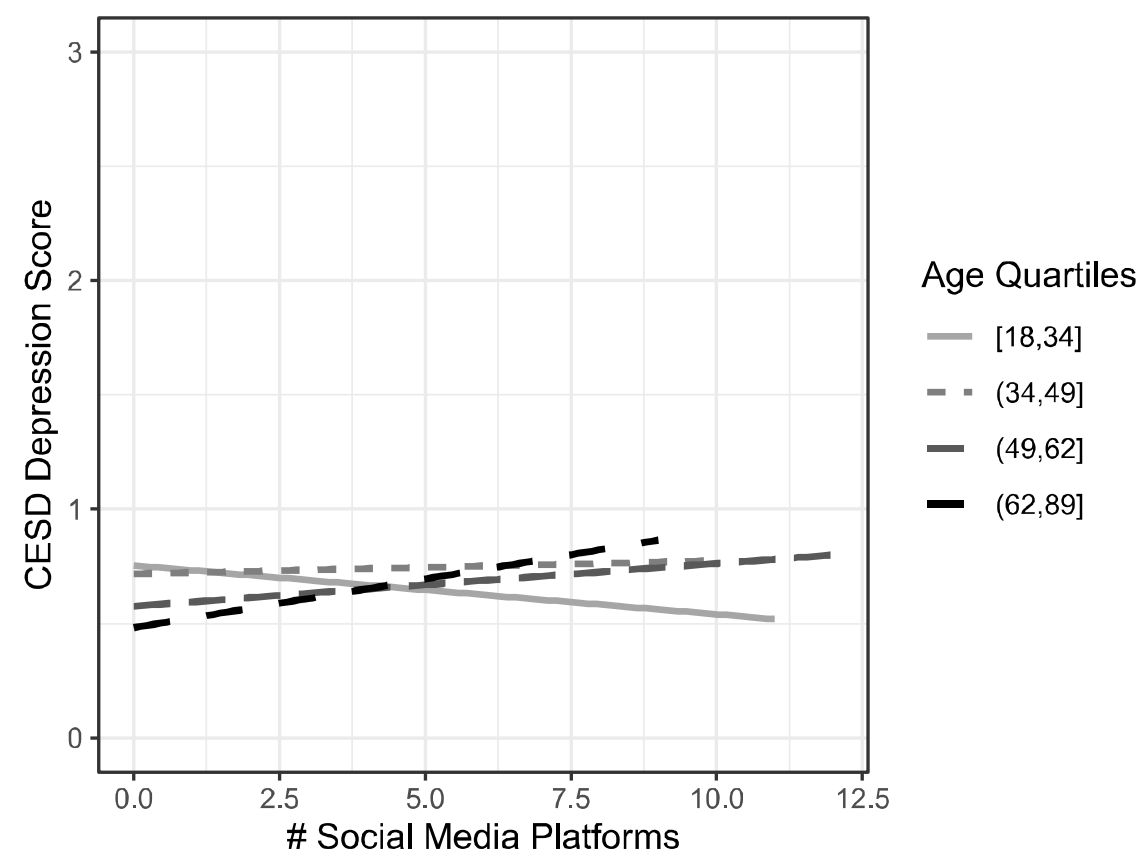

Figure 3. Linear regression lines for the interaction of social media usage intensity and age on symptoms of depression, plotted by age quartiles.

\subsection{Specific platform use}

Finally, we analyzed if any specific social media platforms were associated with personal or social well-being. In general, almost all social media platforms were used more by younger than by older people, with the interesting exception of Classmates - a platform to connect with former peers from all stages of life (kindergarten to workplace), but especially focused on former high school peers. The site hosts a collection of online yearbooks with which former classmates can be found. This retrospective focus on connections that happened years or decades ago, combined with its very early founding date (1995) can explain why it is primarily older people who use Classmates. Because of these associations with age, we controlled for age in the subsequent models (Table 3).

Most platforms did not show negative relations to well-being. Facebook usage appeared to be associated with worse health and a higher chance of ever having felt like a mental 
breakdown was approaching, when controlling for the effect of age. Tumblr users reported being unhappier, unhealthier, and less confident in social institutions than people who were not on Tumblr. Tumblr is known for an audience that partially consists of young adults with low wellbeing and an active community where health, especially mental health problems are prominently discussed or turned into communal coping humor. Pinterest use was associated with more happiness and more excitement about one's life, but also with a higher chance of ever having felt like having a mental breakdown. This inconsistent pattern could cast further doubt onto the validity of the breakdown variable as an indicator of well-being. Pinterest and Classmates users both reported spending fewer evenings in social situations, even after for controlling for age.

All other observed associations were positive in nature, such as Twitter being associated with more social trust and a lower chance of having felt like having a breakdown, Snapchat being associated with fewer bad mental health days, WhatsApp being associated with better health and more excitement about life, and LinkedIn being associated with most indicators of personal well-being. LinkedIn focuses especially on working-age adults in higher-paying positions. Thus, people who cannot participate in the labor force (e.g., through severe health or mental health problems) will likely self-select out of the platform. Income predicted levels of well-being (e.g., $r=.21, p<.001$ for happiness). However, after controlling for income, the associations between LinkedIn use and 
Table 3

Standardized linear regression coefficients $(\beta)$ for predicting well-being from use of social media platforms, controlling for age (the

effect of age is shown separately in the second column). Only $\beta$ coefficients significant at $\mathrm{p}<.05$ are shown (see Supplementary Table 4 for the full table with all coefficients).

\begin{tabular}{|c|c|c|c|c|c|c|c|c|c|c|c|c|}
\hline $\begin{array}{l}\text { Social } \\
\text { Media } \\
\text { Platform }\end{array}$ & $\begin{array}{c}r \text { with } \\
\text { age }\end{array}$ & $\begin{array}{c}\text { Happi } \\
\text {-ness }\end{array}$ & Health & $\begin{array}{c}\text { Depre- } \\
\text { ssion }\end{array}$ & $\begin{array}{c}\text { Bad } \\
\text { mental } \\
\text { health } \\
\text { days }\end{array}$ & $\begin{array}{c}\text { Ever } \\
\text { feel like } \\
\text { break- } \\
\text { down }\end{array}$ & $\begin{array}{l}\text { Exciting } \\
\text { vs. dull } \\
\text { life }\end{array}$ & $\begin{array}{c}\text { Financial } \\
\text { satis- } \\
\text { faction }\end{array}$ & $\begin{array}{l}\text { Relation } \\
\text {-ship } \\
\text { satis- } \\
\text { faction }\end{array}$ & $\begin{array}{c}\text { Social } \\
\text { trust }\end{array}$ & $\begin{array}{l}\text { Confidence } \\
\text { in soc. } \\
\text { institutions }\end{array}$ & $\begin{array}{c}\text { Offline } \\
\text { social } \\
\text { contacts }\end{array}$ \\
\hline \# platforms & -.30 & & & & & & .05 & & & $.04+$ & .03 & \\
\hline Facebook & -.16 & & $-.21+$ & & & .27 & & & & & & \\
\hline Twitter & -.22 & & & & & -.22 & .18 & .22 & & .23 & $.22+$ & \\
\hline Tumblr & -.11 & $-.40+$ & $-.76+$ & & & & & & & & $-.27+$ & \\
\hline Snapchat & -.42 & & & & $-.17+$ & & & & & & & $.35+$ \\
\hline Vine & -.14 & & & & & & & & & & & \\
\hline Instagram & -.38 & & & & & & & & & & & \\
\hline Pinterest & $-.03(\mathrm{~ns})$ & .13 & & & & $.31+$ & $.16+$ & & & & & $-.19+$ \\
\hline Flickr & $.06(\mathrm{~ns})$ & & & & & & & & & & & \\
\hline WhatsApp & -.09 & & $.35+$ & & & & .29 & & & & & \\
\hline Classmates & .16 & & & & & & & & & & & $-.34+$ \\
\hline LinkedIn & $.00(\mathrm{~ns})$ & .20 & $.40+$ & -.24 & & & .23 & .19 & & .37 & & \\
\hline Google+ & $-.02(\mathrm{~ns})$ & & & & & & & & & & .14 & \\
\hline
\end{tabular}

+ indicates that the correlation remained significant after controlling for the same set of demographic covariates as presented previously. None of the correlations in this table changed in sign after controlling for these covariates. 
Table 4

Results of propensity-adjusted IPTW regressions of social media use on well-being. IPTW estimate represent means and 95\%

percentiles of 5,000 bootstrapped samples. For comparison, the coefficients from simple, non-adjusted regressions are presented The outcome variables and all continuous predictors were standardized.

\begin{tabular}{|c|c|c|c|}
\hline Outcome & Unadjusted $\beta$ & IPTW average $\beta$ & IPTW 95\% CI \\
\hline \multicolumn{4}{|c|}{ Social media users (1) vs. non-users (0) } \\
\hline Happiness & -0.08 & -0.04 & {$[-0.31,0.20]$} \\
\hline Health & $-0.33^{*}$ & $-0.40 *$ & {$[-0.70,-0.16]$} \\
\hline Depression & 0.21 & 0.12 & {$[-0.15,0.36]$} \\
\hline Bad mental health days & -0.01 & -0.15 & {$[-0.69,0.15]$} \\
\hline Ever breakdown & $0.47 *$ & 0.24 & {$[-0.18,0.61]$} \\
\hline Exciting vs. dull life & -0.02 & 0.02 & {$[-0.29,0.38]$} \\
\hline Financial satisfaction & -0.13 & 0.00 & {$[-0.32,0.21]$} \\
\hline Relationship satisfaction & -0.01 & 0.19 & {$[-0.12,0.53]$} \\
\hline Social trust & 0.08 & 0.19 & {$[-0.06,0.48]$} \\
\hline Confidence in soc. institutions & 0.12 & 0.12 & {$[-0.07,0.30]$} \\
\hline \multicolumn{4}{|c|}{$\begin{array}{l}\text { Intensive social media users }(1 ; 6+\text { platforms }) \text { vs. } \\
\text { moderate users and non-users }(0 ; 0-5 \text { platforms })\end{array}$} \\
\hline Happiness & 0.00 & -0.01 & {$[-0.35,0.32]$} \\
\hline Health & 0.21 & 0.25 & {$[-0.07,0.55]$} \\
\hline Depression & 0.02 & 0.05 & {$[-0.22,0.38]$} \\
\hline Bad mental health days & 0.12 & -0.05 & {$[-0.25,0.29]$} \\
\hline Ever breakdown & 0.03 & -0.06 & {$[-0.42,0.29]$} \\
\hline Exciting vs. dull life & $0.30^{*}$ & 0.33 & {$[-0.24,0.67]$} \\
\hline Financial satisfaction & -0.07 & -0.12 & {$[-0.37,0.36]$} \\
\hline Relationship satisfaction & 0.19 & 0.26 & {$[-0.13,0.52]$} \\
\hline Social trust & 0.01 & 0.15 & {$[-0.09,0.35]$} \\
\hline Confidence in soc. institutions & 0.13 & 0.15 & {$[-0.15,0.92]$} \\
\hline
\end{tabular}

$* p<.05$ 
happiness, excitement about life, and financial satisfaction became non-significant. Importantly, no indicator of social media use was associated with relationship satisfaction, again offering no support for a displacement theory according to which online activity should take a toll on the quality of offline social relationships (see Hall et al., 2019; Valkenburg \& Peter, 2007, for related findings).

\subsection{Self-Selection Bias and Propensity-score adjustment.}

Many of the results we presented can reasonably be explained by selection effects related to who decides to use social media, such as the finding that LinkedIn users report higher wellbeing. To reduce selection effects in our analyses and obtain less biased estimates that bring us closer to causal effects (to the extent possible in cross-sectional survey data), we used a propensity score adjustment procedure. In a first step, we calculated propensity scores by obtaining the fitted probabilities from a logistic regression in which binary indicators of social media use and intensive social media use were regressed on various socio-demographic variables - the same set of socio-demographic variables we presented previously, plus region and the year in which participants had started using the internet. In a second step, we used these propensity scores as inverse-probability of treatment (IPTW) weights (Austin, 2011; Austin \& Stuart, 2015) when regressing measures of well-being on the binary indicators of social media use. Following the recommendations of Ridgeway, Kovalchik, Griffin, and Kabeto (2015), we combined these newly-calculated weights with the GSS survey weights by multiplying them. To calculate standard errors and confidence intervals, this procedure was bootstrapped with 5,000 replicates: We computed bias-corrected and accelerated confidence intervals based on these results.

Overall, there was no evidence for an effect of either regular or intensive social media use on well-being (Table 4). Most effect sizes were small, all confidence intervals but one included 
zero, and there was no consistent pattern across the different indicators of well-being. The only effect for which zero is not included in the confidence interval is the association of social media use (vs. non-use) on health: Both before and after propensity adjustment, social media users on average report poorer health than non-users. This finding, however, does not extend to the intensity of social media use, where if anything, the tendency is for intensive users to report better health than moderate users and non-users combined. The effect of social media use (vs. non-use) on ever having felt like having a breakdown was substantially reduced when adjusting for the propensity score (on average, $12 \%$ of the range vs. $25 \%$ without adjustment) and in $22 \%$ of the bootstrap replicates, the effect was zero or smaller. After adjustment, intensive social media users on average were also more likely to report low financial satisfaction and high social trust compared to moderate users or non-users, but again the results were too volatile to be considered reliable and both confidence intervals included zero. In a nutshell, results from propensity adjustment thus supported the finding that effects of social media use on well-being tend to be small and inconsistent.

\section{Discussion and Conclusions}

To summarize: 1) Intensive users of social media tended to be young, female, more likely to be Black than Hispanic, with higher-SES, more religious, and more likely to be from foreignborn families compared to both non-users and moderate users. 2) Multi-platform social media usage generally did not affect personal or social well-being, but results depended on 3) age and 4) which specific platforms were used. When associations emerged, they either were positive in nature or 5) most consistent with a self-selection effect of pre-existing differences (rather than a causal effect from social media to well-being), a result that was confirmed by models that adjusted for the propensity to use social media (or use it intensively) based on a variety of socio- 
demographic covariates. Symptoms of depression were the only exception; they were slightly higher with higher social media usage among middle-aged to older adults, but not for young to middle-aged adults (18-34). For individual social media platforms, there was no consistent pattern of effects either - some platforms' users report lower well-being on some of the indicators (e.g., Facebook, Tumblr, Pinterest), whereas other platforms' users report higher wellbeing on several indicators (e.g., Twitter, Snapchat, Pinterest, LinkedIn).

This overall absence of consistent effects on well-being is at odds with several publications that had argued for detrimental effects of social media use generally (e.g., Kross et al., 2013; Twenge \& Campbell, 2019) and multi-platform social media use specifically (Hardy \& Castonguay, 2018; Primack et al., 2017; Vannucci et al., 2019). It is, however, in line with a growing literature that suggests that effects of social media on well-being may be smaller than previously suggested (e.g., M. Appel et al., 2019; Coyne et al., 2020; Huang, 2017; Jensen et al., 2019; Orben et al., 2019; Orben \& Przybylski, 2019). Our analyses extend the findings of Hardy and Castonguay (2018) who, using the same dataset, found detrimental effects of multi-platform use on the chance of ever having felt like a mental breakdown was imminent, more so for older than for younger adults: Examining a larger number of social media platforms, a larger number of well-being indicators, and using more stringent adjustments for selection bias, we were not able to replicate their findings for any variable except for an interaction of age and social media use on symptoms of depression. Several influential publications that cautioned against social media use were specifically concerned about youth (Balbo, 2018; Kross et al., 2013; Twenge \& Campbell, 2019). The 2016 GSS data do not support these concerns: If anything, the patterns indicated that comparatively older adults (35+) may be more at risk of experiencing depressive symptoms when they are also using many social media platforms (Figure 3), whereas we 
observed no such risk for younger adults. It should, however, be noted that the GSS data did not include adolescents below the age of 18 and can thus speak only to well-being among adults.

The finding that people of high SES and young people are more likely to be intensive users is in line with findings that they are also more likely to be using social media at all (Perrin \& Anderson, 2019). In contrast, although these existing data on social media use show few overall differences between Hispanic and non-Hispanic people, Hispanic people were less likely to be intensive users, highlighting the importance of distinguishing between whether someone uses a social media platform and how many platforms they are using. In our study, people with more foreign-born relatives were also slightly more likely to be using many social media platforms. Network theories of migration have posited that social media networks may both facilitate migration decisions by assuring social support at the destination location and be used as a resource after migration has taken place to connect with friends and family in both origin and destination locations (Dekker \& Engbersen, 2014; Komito, 2011; Massey et al., 1993), but there have been few empirical tests of this assertion (Chi et al., 2020; Gil-Clavel \& Zagheni, 2019). Our data support these theories by showing that people from migrant families may indeed be more likely to connect with others on a variety of platforms. Interestingly, we also found that more religious people were more likely to be intensive users. There has not been much prior research on the role of religion in multi-platform use, but these results fit with existing data on religious identity being associated with larger social networks (e.g., Lim \& Putnam, 2010) and Christians using more words related to social connectedness on Twitter than atheists (e.g., “friend”; Ritter et al., 2014).

The findings from this research can be useful first for those who seek to understand who is using social media more versus less intensively. If future research uncovers effects of intensive 
social media use on other health variables that have so far remained unexamined, the characterization of intensive users in the present work can help to identify groups that are at particularly high (or low) risk. Second, this work contributes to the ongoing discussion on whether social media use is overall harmful, helpful, or neutral for the well-being of populations in the digital age. The results from the 2016 GSS overall suggest that social media use does not have strong implications for either personal or social measures of well-being, and that specific patterns of usage (e.g., specific platforms, or usage in specific age groups) can have harmful and helpful effects alike. Social media has undeniably changed people's lives by offering a completely new form of infrastructure with which people can and do obtain information, share their opinions, and communicate with others. Now that this new infrastructure exists, however, using it versus not using it may not have strong effects on well-being. The current results thus support the idea that social media has changed the surface form of communication rather than both form and well-being derived from this communication - just as with offline interactions, well-being may depend more on what, specifically, happens in an interaction (e.g., Bessière et al., 2010; Park et al., 2009; Rae \& Lonborg, 2015; Valkenburg et al., 2006) rather than on the medium of communication. In the early days of internet research, after initial concerns about detrimental effects on well-being, many studies found small, null, or even positive effects and the internet appeared as "a new way of doing old things" (Tyler, 2002); it is possible that social media research is heading in a similar direction.

Third, our findings may be of interest to health and mental health professionals. For example, there have been calls for clinicians to ask their clients about their social media use, and, if the client is using many social media platforms, to treat this as a warning sign for mental health problems or dysfunctional behavior. Our results caution against using multi-platform 
social media use as such a warning sign to avoid over-pathologizing commonplace and potentially harmless behaviors such as social media use. Instead, our results can offer more specific guidance for clinicians: Ask for more details about how, how much, and for which purposes clients are using social media to determine whether a problem exists (and if so, where it lies), familiarize yourself with the characteristics of different social media platforms and their associated characteristics (e.g., Tumblr tends to be used more by people with low well-being, whereas Snapchat use appears to be neither an indicator nor a cause of low well-being), and be aware that older people who are heavy users of social media may be at higher risk of depression than younger people with comparable social media usage.

Because the social media module was included in the GSS only once to date, this dataset offers only a cross-sectional snapshot of a single time point. It is possible that on the macrolevel, population well-being changed when social media first reached widespread popularity or that on the micro-level, increases or decreases in social media use change well-being, but such a historical analysis is beyond the scope of this current paper. Similarly, macro-level social media use may have indirect consequences for individual well-being that our analysis cannot capture, such as other people gossiping about a person online, regardless of whether that person is on social media or not. Even though our findings in this article cannot speak to historical or macrolevel developments, they offer relevant and timely information going forward: With social media already a ubiquitous part of societal functioning and interpersonal communication patterns, should people avoid social media to overall improve population health? The present results suggest that this step may not be necessary because the intensity of social media use is not consistently related to poorer or better well-being. Future studies should collect longitudinal data on multi-platform use to extend these findings to intra-individual changes over time. Although 
the current dataset was based on a representative sample, it included only US residents and how transferable the results are to other structural and cultural contexts is an empirical question that should be examined by future work. The answer will likely depend on the purposes for which social media are being used in other countries. Finally, our results are not meant to indicate that problematic social media use does not exist. Like any other activity, social media use can become dysfunctional if it consumes excessive amounts of time and if users no longer feel like they can control their social media use (Andreassen, 2015; M. D. Griffiths, 2013; LaRose et al., 2014), or if it is used in ways that reinforce harmful attitudes (e.g., radicalization of political attitudes, Grover \& Mark, 2019; or potentially unhealthy views on body image, Holland \& Tiggemann, 2016) or harmful behaviors (e.g., by normalizing or encouraging behaviors such as disordered eating, Branley \& Covey, 2017; or self-harm, Dyson et al., 2016). The GSS does not include data on such specific behaviors, but its data on well-being indicate that on average, US adults appear to use social media in ways that do not pose such problems.

To conclude, the 2016 wave of the General Social Survey offers nationally representative data on social media use and well-being in the United States. We provide a socio-demographic characterization of intensive social media users who have profiles on a number of social media platforms and find few detrimental as well as few positive associations of intensive social media use with both personal mental health and the quality of offline social relationships. These findings contribute to a growing literature on the transformative effects of the digital revolution and suggest that for typical patterns of usage, social media as a new medium of communication may not impact well-being. 


\section{References}

Aalbers, G., McNally, R. J., Heeren, A., de Wit, S., \& Fried, E. I. (2019). Social media and depression symptoms: A network perspective. Journal of Experimental Psychology: General, 148(8), 1454-1462. https://doi.org/10.1037/xge0000528

Abbey, A., Abramis, D. J., \& Caplan, R. D. (1985). Effects of Different Sources of Social support and Social Conflict on Emotional Well-Being. Basic and Applied Social Psychology, 6(2), 111-129. https://doi.org/10.1207/s15324834basp0602_2

Andreassen, C. S. (2015). Online Social Network Site Addiction: A Comprehensive Review. Current Addiction Reports, 2(2), 175-184. https://doi.org/10.1007/s40429-015-0056-9

Appel, H., Gerlach, A. L., \& Crusius, J. (2016). The interplay between Facebook use, social comparison, envy, and depression. Current Opinion in Psychology, 9, 44-49. https://doi.org/10.1016/j.copsyc.2015.10.006

Appel, M., Marker, C., \& Gnambs, T. (2019). Are social media ruining our lives? A review of meta-analytic evidence. Review of General Psychology. https://doi.org/10.1177/1089268019880891

Austin, P. C. (2011). An Introduction to Propensity Score Methods for Reducing the Effects of Confounding in Observational Studies. Multivariate Behavioral Research, 46(3), 399424. https://doi.org/10.1080/00273171.2011.568786

Austin, P. C., \& Stuart, E. A. (2015). Moving towards best practice when using inverse probability of treatment weighting (IPTW) using the propensity score to estimate causal treatment effects in observational studies. Statistics in Medicine, 34(28), 3661-3679. https://doi.org/10.1002/sim.6607 
Balbo, N. (2018). The Mental Toll of Being Connected (Policy Brief) (No. 19; Population Europe Policy Briefs). https://population-europe.eu/policy-brief/mental-toll-being-connected

Berkman, L. F., \& Syme, S. L. (1979). Social networks, host resistance, and mortality: A nineyear follow-up study of Alameda County residents. American Journal of Epidemiology, 109(2), 186-204. https://doi.org/10.1093/oxfordjournals.aje.a112674

Bessière, K., Pressman, S., Kiesler, S., \& Kraut, R. (2010). Effects of Internet Use on Health and Depression: A Longitudinal Study. Journal of Medical Internet Research, 12(1), e6. https://doi.org/10.2196/jmir.1149

boyd, danah m, \& Ellison, N. B. (2007). Social network sites: Definition, history, and scholarship. Journal of Computer-Mediated Communication, 13(1), 210-230. https://doi.org/10.1111/j.1083-6101.2007.00393.x

Branley, D. B., \& Covey, J. (2017). Pro-ana versus Pro-recovery: A Content Analytic Comparison of Social Media Users' Communication about Eating Disorders on Twitter and Tumblr. Frontiers in Psychology, 8. https://doi.org/10.3389/fpsyg.2017.01356

Chi, G., State, B., Blumenstock, J. E., \& Adamic, L. (2020). Who Ties the World Together? Evidence from a Large Online Social Network. In H. Cherifi, S. Gaito, J. F. Mendes, E. Moro, \& L. M. Rocha (Eds.), Complex Networks and Their Applications VIII (pp. 451465). Springer International Publishing. https://doi.org/10.1007/978-3-030-36683-4_37

Coyne, S. M., Rogers, A. A., Zurcher, J. D., Stockdale, L., \& Booth, M. (2020). Does time spent using social media impact mental health?: An eight year longitudinal study. Computers in Human Behavior, 104, 106160. https://doi.org/10.1016/j.chb.2019.106160

Cronbach, L. J. (1951). Coefficient alpha and the internal structure of tests. Psychometrika, 16(3), 297-334. https://doi.org/10.1007/BF02310555 
Dekker, R., \& Engbersen, G. (2014). How social media transform migrant networks and facilitate migration. Global Networks, 14(4), 401-418. https://doi.org/10.1111/glob.12040

DeSalvo, K. B., Bloser, N., Reynolds, K., He, J., \& Muntner, P. (2006). Mortality prediction with a single general self-rated health question. Journal of General Internal Medicine, 21(3), 267. https://doi.org/10.1111/j.1525-1497.2005.00291.x

Diener, E., Napa Scollon, C., \& Lucas, R. E. (2003). The evolving concept of subjective wellbeing: The multifaceted nature of happiness. In Advances in Cell Aging and Gerontology (Vol. 15, pp. 187-219). Elsevier. https://doi.org/10.1016/S1566-3124(03)15007-9

Diener, E., \& Suh, M. E. (1997). Subjective Well-Being and Age: An International Analysis. Annual Review of Gerontology and Geriatrics, 17(1), 304-324. https://doi.org/10.1891/0198-8794.17.1.304

Doğan, U. (2016). Effects of Social Network Use on Happiness, Psychological Well-being, and Life Satisfaction of High School Students: Case of Facebook and Twitter. Education and Science, 41(183), 217-231. https://doi.org/10.15390/EB.2016.4616

Dyson, M. P., Hartling, L., Shulhan, J., Chisholm, A., Milne, A., Sundar, P., Scott, S. D., \& Newton, A. S. (2016). A Systematic Review of Social Media Use to Discuss and View Deliberate Self-Harm Acts. PLOS ONE, 11(5), e0155813. https://doi.org/10.1371/journal.pone.0155813

Ellison, N. B., Steinfield, C., \& Lampe, C. (2007). The Benefits of Facebook "Friends:” Social Capital and College Students' Use of Online Social Network Sites. Journal of ComputerMediated Communication, 12(4), 1143-1168. https://doi.org/10.1111/j.10836101.2007.00367.x 
Faranda, M., \& Roberts, L. D. (2019). Social comparisons on Facebook and offline: The relationship to depressive symptoms. Personality and Individual Differences, 141, 13-17. https://doi.org/10.1016/j.paid.2018.12.012

Fergie, G., Hunt, K., \& Hilton, S. (2016). Social media as a space for support: Young adults' perspectives on producing and consuming user-generated content about diabetes and mental health. Social Science \& Medicine, 170, 46-54. https://doi.org/10.1016/j.socscimed.2016.10.006

Gerber, J. P., Wheeler, L., \& Suls, J. (2018). A social comparison theory meta-analysis 60+ years on. Psychological Bulletin, 144(2), 177-197. https://doi.org/10.1037/bu10000127

Gil-Clavel, S., \& Zagheni, E. (2019). Demographic Differentials in Facebook Usage around the World. Proceedings of the International AAAI Conference on Web and Social Media, 13, $647-650$.

Gowen, K., Deschaine, M., Gruttadara, D., \& Markey, D. (2012). Young adults with mental health conditions and social networking websites: Seeking tools to build community. Psychiatric Rehabilitation Journal, 35(3), 345-350.

https://doi.org/10.2975/35.3.2012.245.250

Griffiths, K. M., Calear, A. L., \& Banfield, M. (2009). Systematic Review on Internet Support Groups (ISGs) and Depression (1): Do ISGs Reduce Depressive Symptoms? Journal of Medical Internet Research, 11(3), e40. https://doi.org/10.2196/jmir.1270

Griffiths, M. D. (2013). Social Networking Addiction: Emerging Themes and Issues. Journal of Addiction Research \& Therapy, 04(05). https://doi.org/10.4172/2155-6105.1000e118 
Grover, T., \& Mark, G. (2019). Detecting Potential Warning Behaviors of Ideological Radicalization in an Alt-Right Subreddit. Proceedings of the International AAAI Conference on Web and Social Media, 13, 193-204.

Hall, J. A., Kearney, M. W., \& Xing, C. (2019). Two tests of social displacement through social media use. Information, Communication \& Society, 22(10), 1396-1413. https://doi.org/10.1080/1369118X.2018.1430162

Hardy, B. W., \& Castonguay, J. (2018). The moderating role of age in the relationship between social media use and mental well-being: An analysis of the 2016 General Social Survey. Computers in Human Behavior, 85, 282-290. https://doi.org/10.1016/j.chb.2018.04.005

Helliwell, J. F., \& Putnam, R. D. (2004). The social context of well-being. Philosophical Transactions of the Royal Society B: Biological Sciences, 359(1449), 1435-1446. https://doi.org/10.1098/rstb.2004.1522

Holland, G., \& Tiggemann, M. (2016). A systematic review of the impact of the use of social networking sites on body image and disordered eating outcomes. Body Image, 17, 100110. https://doi.org/10.1016/j.bodyim.2016.02.008

Huang, C. (2017). Time Spent on Social Network Sites and Psychological Well-Being: A MetaAnalysis. Cyberpsychology, Behavior, and Social Networking, 20(6), 346-354. https://doi.org/10.1089/cyber.2016.0758

Jensen, M., George, M. J., Russell, M. R., \& Odgers, C. L. (2019). Young Adolescents’ Digital Technology Use and Mental Health Symptoms: Little Evidence of Longitudinal or Daily Linkages. Clinical Psychological Science, 2167702619859336. https://doi.org/10.1177/2167702619859336 
Komito, L. (2011). Social media and migration: Virtual community 2.0. Journal of the American Society for Information Science and Technology, 62(6), 1075-1086. https://doi.org/10.1002/asi.21517

Kraut, R., Kiesler, S., Boneva, B., Cummings, J. N., Helgeson, V., \& Crawford, A. M. (2002). Internet paradox revisited. Journal of Social Issues, 58(1), 49-74. https://doi.org/10.1111/1540-4560.00248

Kraut, R., Patterson, M., Lundmark, V., Kiesler, S. B., Mukopadhyay, T., \& Scherlis, W. L. (1998). Internet paradox. A social technology that reduces social involvement and psychological well-being? American Psychologist, 53(9), 1017-1031. https://doi.org/10.1037/0003-066x.53.9.1017

Kross, E., Verduyn, P., Demiralp, E., Park, J., Lee, D. S., Lin, N., Shablack, H., Jonides, J., \& Ybarra, O. (2013). Facebook Use Predicts Declines in Subjective Well-Being in Young Adults. PLOS ONE, 8(8), e69841. https://doi.org/10.1371/journal.pone.0069841

LaRose, R., Connolly, R., Lee, H., Li, K., \& Hales, K. D. (2014). Connection Overload? A Cross Cultural Study of the Consequences of Social Media Connection: Information Systems Management: Vol 31, No 1. Information Systems Management, 31, 59-73.

Lee, K.-T., Noh, M.-J., \& Koo, D.-M. (2013). Lonely People Are No Longer Lonely on Social Networking Sites: The Mediating Role of Self-Disclosure and Social Support. Cyberpsychology, Behavior, and Social Networking, 16(6), 413-418. https://doi.org/10.1089/cyber.2012.0553

Lepore, S. J. (1992). Social conflict, social support, and psychological distress: Evidence of cross-domain buffering effects. Journal of Personality and Social Psychology, 63(5), 857-867. https://doi.org/10.1037/0022-3514.63.5.857 
Levenson, J. C., Shensa, A., Sidani, J. E., Colditz, J. B., \& Primack, B. A. (2016). The Association between Social Media Use and Sleep Disturbance among Young Adults. Preventive Medicine, 85, 36-41. https://doi.org/10.1016/j.ypmed.2016.01.001

Lim, C., \& Putnam, R. D. (2010). Religion, Social Networks, and Life Satisfaction. American Sociological Review, 75(6), 914-933. JSTOR.

Luo, Y., \& Waite, L. J. (2005). The Impact of Childhood and Adult SES on Physical, Mental, and Cognitive Well-Being in Later Life. The Journals of Gerontology: Series B, 60(2), S93-S101. https://doi.org/10.1093/geronb/60.2.S93

Massey, D. S., Arango, J., Hugo, G., Kouaouci, A., Pellegrino, A., \& Taylor, J. E. (1993). Theories of International Migration: A Review and Appraisal. Population and Development Review, 19(3), 431-466. JSTOR. https://doi.org/10.2307/2938462

Myers, T. A., \& Crowther, J. H. (2009). Social comparison as a predictor of body dissatisfaction: A meta-analytic review. Journal of Abnormal Psychology, 118(4), 683. https://doi.org/10.1037/a0016763

Nie, N. H. (2001). Sociability, Interpersonal Relations, and the Internet: Reconciling Conflicting Findings. American Behavioral Scientist, 45(3), 420-435. https://doi.org/10.1177/00027640121957277

Orben, A., Dienlin, T., \& Przybylski, A. K. (2019). Social media's enduring effect on adolescent life satisfaction. Proceedings of the National Academy of Sciences, 116(21), 1022610228. https://doi.org/10.1073/pnas.1902058116

Orben, A., \& Przybylski, A. K. (2019). The association between adolescent well-being and digital technology use. Nature Human Behaviour, 3(2), 173-182. https://doi.org/10.1038/s41562-018-0506-1 
Park, N., Kee, K. F., \& Valenzuela, S. (2009). Being Immersed in Social Networking Environment: Facebook Groups, Uses and Gratifications, and Social Outcomes. CyberPsychology \& Behavior, 12(6), 729-733. https://doi.org/10.1089/cpb.2009.0003

Perrin, A., \& Anderson, M. (2019). Share of U.S. adults using social media, including Facebook, is mostly unchanged since 2018 [Social media update 2019]. Pew Research Center. https://www.pewresearch.org/fact-tank/2019/04/10/share-of-u-s-adults-using-socialmedia-including-facebook-is-mostly-unchanged-since-2018/

Pinquart, M., \& Sörensen, S. (2000). Influences of socioeconomic status, social network, and competence on subjective well-being in later life: A meta-analysis. Psychology and Aging, 15(2), 187-224. https://doi.org/10.1037/0882-7974.15.2.187

Primack, B. A., Shensa, A., Escobar-Viera, C. G., Barrett, E. L., Sidani, J. E., Colditz, J. B., \& James, A. E. (2017). Use of multiple social media platforms and symptoms of depression and anxiety: A nationally-representative study among U.S. young adults. Computers in Human Behavior, 69, 1-9. https://doi.org/10.1016/j.chb.2016.11.013

Radloff, L. S. (1977). The CES-D Scale: A Self-Report Depression Scale for Research in the General Population. Applied Psychological Measurement, 1(3), 385-401. https://doi.org/10.1177/014662167700100306

Rae, J. R., \& Lonborg, S. D. (2015). Do motivations for using Facebook moderate the association between Facebook use and psychological well-being? Frontiers in Psychology, 6. https://doi.org/10.3389/fpsyg.2015.00771

Ridgeway, G., Kovalchik, S. A., Griffin, B. A., \& Kabeto, M. U. (2015). Propensity Score Analysis with Survey Weighted Data. Journal of Causal Inference, 3(2), 237-249. https://doi.org/10.1515/jci-2014-0039 
Ritter, R. S., Preston, J. L., \& Hernandez, I. (2014). Happy Tweets: Christians Are Happier, More Socially Connected, and Less Analytical Than Atheists on Twitter. Social Psychological and Personality Science, 5(2), 243-249. https://doi.org/10.1177/1948550613492345

Schnittker, J., \& Bacak, V. (2014). The Increasing Predictive Validity of Self-Rated Health. PLOS ONE, 9(1), e84933. https://doi.org/10.1371/journal.pone.0084933

Selkie, E., Adkins, V., Masters, E., Bajpai, A., \& Shumer, D. (2019). Transgender adolescents' uses of social media for social support. Journal of Adolescent Health. https://doi.org/10.1016/j.jadohealth.2019.08.011

Smith, T. W., Davern, M., Freese, J., \& Morgan, S. L. (2019). General Social Surveys, 1972 2018 [machine-readable data file + codebook]. NORC at the University of Chicago.

Song, H., Zmyslinski-Seelig, A., Kim, J., Drent, A., Victor, A., Omori, K., \& Allen, M. (2014). Does Facebook make you lonely?: A meta analysis. Computers in Human Behavior, 36, 446-452. https://doi.org/10.1016/j.chb.2014.04.011

Szabo, A., \& Hopkinson, K. L. (2007). Negative psychological effects of watching the news in the television: Relaxation or another intervention may be needed to buffer them! International Journal of Behavioral Medicine, 14(2), 57-62. https://doi.org/10.1007/BF03004169

Twenge, J. M., \& Campbell, W. K. (2019). Media Use Is Linked to Lower Psychological WellBeing: Evidence from Three Datasets. Psychiatric Quarterly, 90(2), 311-331. https://doi.org/10.1007/s11126-019-09630-7

Twenge, J. M., Joiner, T. E., Rogers, M. L., \& Martin, G. N. (2018). Increases in Depressive Symptoms, Suicide-Related Outcomes, and Suicide Rates Among U.S. Adolescents After 
2010 and Links to Increased New Media Screen Time. Clinical Psychological Science, 6(1), 3-17. https://doi.org/10.1177/2167702617723376

Tyler, T. R. (2002). Is the Internet Changing Social Life? It Seems the More Things Change, the More They Stay the Same. Journal of Social Issues, 58(1), 195-205. https://doi.org/10.1111/1540-4560.00256

Valkenburg, P. M., \& Peter, J. (2007). Online Communication and Adolescent Well-Being: Testing the Stimulation versus the Displacement Hypothesis. Journal of ComputerMediated Communication, 12(4), 1169-1182. https://doi.org/10.1111/j.10836101.2007.00368.x

Valkenburg, P. M., Peter, J., \& Schouten, A. P. (2006). Friend networking sites and their relationship to adolescents' well-being and social self-esteem. Cyberpsychology \& Behavior: The Impact of the Internet, Multimedia and Virtual Reality on Behavior and Society, 9(5), 584-590. https://doi.org/10.1089/cpb.2006.9.584

van der Velden, P. G., Setti, I., van der Meulen, E., \& Das, M. (2019). Does social networking sites use predict mental health and sleep problems when prior problems and loneliness are taken into account? A population-based prospective study. Computers in Human Behavior, 93, 200-209. https://doi.org/10.1016/j.chb.2018.11.047

Vannucci, A., Ohannessian, C. M., \& Gagnon, S. (2019). Use of Multiple Social Media Platforms in Relation to Psychological Functioning in Emerging Adults. Emerging Adulthood, 7(6), 501-506. https://doi.org/10.1177/2167696818782309

Veitch, R., \& Griffitt, W. (1976). Good News - Bad News: Affective and Interpersonal Effects. Journal of Applied Social Psychology, 6(1), 69-75. https://doi.org/10.1111/j.15591816.1976.tb01313.x 
Wang, J.-L., Wang, H.-Z., Gaskin, J., \& Hawk, S. (2017). The Mediating Roles of Upward Social Comparison and Self-esteem and the Moderating Role of Social Comparison Orientation in the Association between Social Networking Site Usage and Subjective Well-Being. Frontiers in Psychology, 8. https://doi.org/10.3389/fpsyg.2017.00771 we are social, \& Hootsuite. (2020). Digital 2020: 3.8 billion people use social media.

https://wearesocial.com/blog/2020/01/digital-2020-3-8-billion-people-use-social-media Yu, R. P., McCammon, R. J., Ellison, N. B., \& Langa, K. M. (2016). The relationships that matter: Social network site use and social wellbeing among older adults in the United States of America. Ageing \& Society, 36(9), 1826-1852.

https://doi.org/10.1017/S0144686X15000677 